\title{
Gluten sensitivity and neurological manifestations
}

\author{
Agostino Berio, ${ }^{1}$ Giuseppe Mangiante, ${ }^{1}$ Gian Luigi Mariottini, ${ }^{2}$ Attilia Piazzi ${ }^{1}$ \\ ${ }^{1}$ Department of Neurosciences, Rehabilitation, Ophthalmology, Genetics, Mother's and Pediatric \\ Sciences, University of Genoa, Genoa; ${ }^{2}$ Department of Earth, Environment and Life Sciences, \\ University of Genoa, Genoa, Italy
}

\begin{abstract}
The authors report on six cases of gluten-sensitivity, also defined non-celiac gluten sensitivity, characterized by abdominal features (diarrhea, bloating, pain), genetic positivity for predisposition to celiac disease (DQB1* 02 in all cases; DQA1*05 in three; DQA1*02 in two, DQB1*03 in two), negative anti-t-Transglutaminase antibodies, normal mucosa on biopsy in four cases, type 1 of Marsh in one case. The subjects presented frequent central nervous system (CNS) symptoms: headache in three patients, somnolence in one, electroencephalogram aspecific alterations in three (in two of them with previous seizures), leptomeningeal cyst in one, intracranial calcification in one, cerebral gliosis in two. After a gluten-free diet, all intestinal and clinical CNS features remitted, but re-appeared after gluten reintroduction. On the basis of the neurological signs, the authors stress the relevance of immune innate system in the pathogenesis of these cases with possible subsequent evolution on immune adaptive system involvement.
\end{abstract}

\section{Introduction}

The individuals with human leukocyte antigens (HLA) DQ2 and DQ8 are genetically susceptible to an abnormal immune responsive-

Correspondence: Agostino Berio, Department of Neurosciences, Rehabilitation, Ophthalmology, Genetics, Mother's and Pediatric Sciences, University of Genova, Largo G. Gaslini 5, 16100 Genoa, Italy.

E-mail: agostinoberio@ospedale-gaslini.ge.it

Key words: Gluten sensitivity; Non-celiac gluten sensitivity; HLA; EEG; Gliosis; Gluten-free diet.

Conflict of interest: the authors declare no potential conflict of interest.

Received for publication: 29 June 2015 .

Revision received: 13 November 2015.

Accepted for publication: 20 November 2015.

(C) Copyright A. Berio et al., 2015

Licensee PAGEPress, Italy

Journal of Biological Research 2015; 88:5405

doi:10.4081/jbr.2015.5405

This article is distributed under the terms of the Creative Commons Attribution Noncommercial License (by-nc 3.0) which permits any noncommercial use, distribution, and reproduction in any medium, provided the original author(s) and source are credited. ness triggered by gluten ingestion. ${ }^{1}$ In predisposed subjects, gluten may cause the celiac disease (CD), i.e. an aberrant immune response in the small bowel mucosa ${ }^{2,3}$ with T- and B-lymphocyte activation, production of anti-t-Transglutaminase (anti-tTg) antibodies, and subsequent enteropathy. ${ }^{4,5} \mathrm{CD} 3+$ and $\mathrm{CD} 4+\mathrm{T}$ cells may be isolated from the intestinal mucosa of celiac patients, but there is evidence that early induction of an inflammatory response to gluten ingestion precedes the antigen T cell response. ${ }^{6}$ As a matter of fact, a gliadin fragment can activate the bowel innate immune system (macrophages, monocytes), producing interferons which induce the adaptive immune system response. Interleukin 15, moved by immune innate system, maintains in permanent activation the adaptive system in $\mathrm{CD}{ }^{7}$

Although CD was considered in the past as a gluten enteropathy, recently the clinical notion has been expanded and at present it is thought to be multi-system autoimmune disorder ${ }^{8}$ with intestinal or extraintestinal manifestations or asyntomatic course..$^{9}$

Among the extraintestinal symptoms, some papers report the neurological conditions associated with CD and typical enteropathy, ${ }^{10}$ others retail neurological manifestations in asymptomatic patients with immune system involvement of the central nervous system (CNS), skin (dermatitis herpetiformis), and other tissues. ${ }^{8}$ The neurological manifestations can occur without a histological evidence of bowel involvement. ${ }^{11}$ In recent years, a novel clinical entity was proposed: the non-celiac gluten sensitivity ${ }^{12,13}$ or gluten sensitivity ${ }^{14,15}$ (GS). GS is a disorder more frequent in adults than in children, characterized by some gastrointestinal features, such as abdominal pain and bloating, diarrhea, hard digestion, and sometimes by other extra-intestinal associated symptoms such as headache, somnolence, depression, low attention, muscular and/or articular pain, eczema, chronic fatigue. All these symptoms occur after gluten ingestion, but remit after gluten elimination from the diet and relapse after gluten reintroduction. These patients are anti-tTg and anti-endomisium negative, prick-test and rast test negative for wheat, and sometimes anti-gliadin positive. Duodenal biopsy demonstrates no (or minimally positive) alterations (grade $0-1$ of Marsh classification) ${ }^{2}$ intraepithelial lymphocytes (IELs) are intermediate between CD and controls (>50/100 enterocytes). In 50\% of cases, these subjects show the aplotype DQ2 and DQ8 which predispose them to CD. ${ }^{15}$

The pathogenesis of this disorder is thought to be related to the intestinal innate immunity system, i.e. to the first stage of the immunological reaction, as demonstrated by lacking of increase of IL6 , IL-21, interferon gamma in gut mucosa of these patients. ${ }^{16}$ On the contrary, in CD both the innate and the adaptive immune system are known to be involved. $6,14,15$

In the last years, we observed some cases which may be referred to GS. In 12 CD patients diagnosed by classical methods (clinical features, positive anti-tTG antibodies in serum, bowel biopsy) we demonstrated an abnormal electroencephalography (EEG) pattern, which normalized in 5/6 of them in parallel with anti-tTg antibodies normal- 
ization after gluten-free diet. Instead, in subjects with high anti-tTg antibodies subjected to gluten-free diet, EEG showed some irregularity, a condition attributed to the persistence of chronic inflammatory processes in CNS due to a non-compliance of the subjects with the diet and/or to other unknown factors. ${ }^{17}$ In this paper, we report 6 cases responding to GS standards.

\section{Materials and Methods}

Six patients with essentially clinical diagnosis of GS and having intestinal features (abdominal pain, diarrhea, bloating, or both diarrhea and bloating), and sometimes other extra-intestinal stymptoms, such as headache and somnolence, and/or EEG alterations after gluten ingestion, remission after gluten elimination from the diet, and relapse after gluten reintroduction have been included in the study. The patients were antitTG and anti-endomisium negatives with duodenal 0-1 grade biopsy according to Marsh classification. The gastrointestinal symptoms, the EEG recording and the neurological symptoms of these patients have been evaluated before and after gluten free diet administration.

\section{Results}

The results obtained in this research are reported in Table 1. In basal conditions, abdominal pain was observed in 3 patients, diarrhea in 3 , bloating in 3. Extraintestinal CNS symptoms were also present; EEG pattern was aspecifically abnormal in 3 patients, with previous seizures in 2 , headache in 3 , gliosis in 2 , leptomeningeal cyst in 1 , and intracranial calcification in 1 .

All cases presented the genetic HLA predisposition to CD. In all cases anti-tTg antibodies were normal on free diet, the duodenal mucosa was normal in 4 patients and with type 1 of Marsh alteration in one of them. After gluten-free diet introduction (1-2 weeks), the gastrointestinal symptoms as well as headache disappeared; convulsions necessitating EEG control were not observed.

\section{Discussion}

We think that gluten sensitivity may be referred to an immunologic condition. The immune system has evolved in animals and in humans into two parts, i.e. a part responsible for prompt immune action against external agents (infectious or non infectious), called the immune innate system, and another one which recognizes the antigen by specific antigen presenting cells (APCs) and antigen receptors, defined the adaptive immune system. The immune innate system utilizes phagocytic cells (monocytes, macrophages, microglia), and the adaptive immune system employs B and T lymphocytes. Cell-to-cell contact and soluble cytokines are the communication route of both immune systems. Gliadin has the power to induce the activation of both innate and adaptive immune system in bowel. ${ }^{5}$ In $\mathrm{CD}$, the stimulation of innate immune system was demonstrated by production of interleukin 15. The activation of pathogenetic CD4+ T lymphocytes, and interferon gamma demonstrates the immune adaptive system response. ${ }^{7}$

CNS is an immunologically specialized site in which inflammatory and immune reactions are locally originated (innate immunity). Immune reactions can also start in the peripheral tissue (bowel, lymph nodes) and be imported into the CNS by competent immune cells (acquired immunity). ${ }^{18}$ Innate and adaptive immunity can be transformed into each other by various cytokines and Toll-like receptors (TLRs). ${ }^{18}$ CNS may be involved in CD in association with bowel, ${ }^{4,11}$ with other tissues or alone. ${ }^{11}$ Gluten sensitivity was attributed to the possible involvement of innate immunity. ${ }^{9,14}$ In gluten sensitivity the CNS involvement was proposed for autism and schizophrenia, ${ }^{14,15}$ EEG abnormalities, ${ }^{19}$ and epilepsy. ${ }^{17}$

In our subjects predisposed by (HLA) DQ2, the first reaction after gluten introduction could be supposed to occur in bowel, and gluten fractions production could have stimulated the activation of innate immune system with consequent bowel symptoms (diarrhea, boating, abdominal pain) and minimal (grade 0-1) histologic manifestations. The cytokine/interferon production ${ }^{16}$ by immune system may have changed the blood-brain barrier, as was observed in some pathological conditions, ${ }^{18}$ and may have acted as a pro-inflammatory signal in CNS with excitotoxicity, possible TLRs production and microglia activation. ${ }^{20}$

The activation of innate immune system at the periphery can recruit

Table 1. Observed cases of gluten sensitivity.

\begin{tabular}{|c|c|c|c|c|c|c|c|c|c|}
\hline Patient No. & $\begin{array}{c}\text { Age } \\
\text { (years) }\end{array}$ & $\begin{array}{l}\text { Genetics } \\
\text { HLA }\end{array}$ & BCS & Anti-tTg & $\begin{array}{l}\text { Duodenal } \\
\text { biopsy }\end{array}$ & CNS symptoms & EEG & $\begin{array}{l}\text { Other CNS } \\
\text { symptoms }\end{array}$ & $\begin{array}{l}\text { Gluten free } \\
\text { diet results }\end{array}$ \\
\hline 1 & 32 & $\begin{array}{c}\text { DQA1*0201 } \\
\text { DQB1*02 } \\
\text { DQB1*0302 }\end{array}$ & $\begin{array}{l}\text { Diarrhea, } \\
\text { abdominal } \\
\text { pain }\end{array}$ & Negative & Type 1 (Marsh) & Headache & Negative & $\begin{array}{l}\text { Leptomeningeal } \\
\text { cyst }\end{array}$ & Positive \\
\hline 2 & 38 & $\begin{array}{l}\mathrm{DQA1}{ }^{*} 05 \\
\mathrm{DQB1}{ }^{*} 02\end{array}$ & Bloating & Negative & - & Somnolence & $\begin{array}{c}\text { Fronto-temporal } \\
\text { alterations (spikes) }\end{array}$ & $\begin{array}{c}\text { Calcifications, } \\
\text { convulsions }\end{array}$ & Positive \\
\hline 3 & 8 & $\begin{array}{l}\mathrm{DQA1}{ }^{*} 05 \\
\mathrm{DQB1}{ }^{*} 02\end{array}$ & Abdominal pain & Negative & Normal & - & $\begin{array}{l}\text { Centro-temporal } \\
\text { alterations }\end{array}$ & Convulsions & Positive \\
\hline 4 & 41 & $\begin{array}{c}\text { DQA1 }^{*} 02: 01 \\
\text { DQB1 }^{*} 02^{\circ} \\
\text { DQB1 }{ }^{\circ} 0302\end{array}$ & $\begin{array}{l}\text { Diarrhea, } \\
\text { bloating }\end{array}$ & Negative & Normal & Headache & Normal & $\begin{array}{l}\text { Pontine } \\
\text { gliosis }\end{array}$ & Positive \\
\hline 5 & 48 & DQB1*02 & Abdominal pain & Negative & Normal & - & Normal & - & Positive \\
\hline 6 & 37 & $\begin{array}{l}\mathrm{DQA1}{ }^{*} 05 \\
\mathrm{DQB1}{ }^{*} 02\end{array}$ & $\begin{array}{l}\text { Diarrhea, } \\
\text { bloating }\end{array}$ & Negative & Normal & Headache & $\begin{array}{l}\text { Temporo- } \\
\text { occipital R } \\
\text { alterations }\end{array}$ & $\begin{array}{l}\text { Frontal } \\
\text { gliosis L, } \\
\text { fronto-temporal R } \\
\text { gliosis }\end{array}$ & Positive \\
\hline
\end{tabular}

HLA, human leukocyte antigen; BCS, bowel clinical symptoms; Anti-tTg, anti-t-Transglutaminase; CNS, central nervous system; EEG, electroencephalography; R, right; L, left. ${ }^{\circ}$ Only $\beta$ chain. 
inflammation cells into CNS via cytotoxic mediators, glutamic acid and cytokines production. . $^{18,20}$ The presence of neutrophils, macrophages and monocytes in areas of neuronal loss in human epileptic tissue demonstrates that these cells contribute to the neuronal damage by cytokines and glutamate. ${ }^{21}$ These phenomena and the production of glutamate from glutamine ${ }^{22}$ may have produced brain hyperexcitability of neurons and the inflammatory process, ${ }^{8}$ demonstrated by EEG abnormalities in the absence of anti-tTg antibodies. The presence of headache, cerebral cyst and gliosis may be a consequence of the inflammatory processes.

On the other hand, Brottveit and colleagues ${ }^{16}$ demonstrated that gluten sensitive patients showed increased levels of gamma interferon and raised CD3+-T cell at baseline after gluten challenge. These findings indicate a possible activation of the immune adaptive component in GS. In these subjects the adaptive immune system activation could be subsequent and eventually signaled by the production of anti-tTg antibodies, and/or possibly of other autoantibodies, as demonstrated in other diseases and in other epilepsy-associated congenital diseases such as Kearns-Sayre Syndrome ${ }^{23}$ and Dravet Syndrome. ${ }^{24}$

Alternatively, gluten fractions in GS may stimulate directly phagocytic cells (macrophages, monocytes) in bowel, with production of intestinal symptoms, and glia in CNS, with EEG abnormalities, headache and gliosis.

It will be important to re-evaluate in our patients the clinical symptoms, the anti-tTG antibodies (and, in case, also other autoantibodies), and the EEG even though in the absence of convulsions after a more prolonged period.

\section{Conclusions}

In our GS cases with genetic predisposition, the CNS involvement was frequent. This condition provided, to search for clinical, electrophysiological and radiological CNS features seems to be mandatory. Further studies could elucidate the significance of EEG alterations present in our cases and the relationships between gluten and CNS abnormalities in GS.

\section{References}

1. Bürk K, Bösch S, Müller CA, et al. Sporadic cerebellar ataxia associated with gluten sensitivity. Brain 2001;124:1013-9.

2. Marsh MH. The natural history of gluten sensitivity: defining, refining and re-defining. Q J Med 1995;85:9-13.

3. Marsh MN. Gluten, major histocompatibility complex, and the small intestine. A molecular and immunobiologic approach to the spectrum of gluten sensitivity ('celiac sprue'). Gastroenterology 1992;102:330-54.

4. Kieslich M, Errázuriz G, Posselt HG, et al. Brain white-matter lesions in celiac disease: a prospective study of 75 diet-treated patients. Pediatrics 2001;108:1-4.
5. Gianfrani C, Auricchio S. La malattia celiaca: la ricerca oggi e le prospettive future. Prospettive in Pediatria 2008;38:18-26.

6. Maiuri L, Picarelli A, Boirivant M, et al. Definition of the initial immunologic modifications upon in vitro gliadin challenge in the small intestine of celiac patients. Gastroenterology 1996;110:1368-78.

7. Maiuri L, Ciacci C, Ricciardelli I, et al. Association between innate response to gliadin and activation of pathogenic T cells in coeliac disease. Lancet 2003;362:30-7.

8. Zelnik N, Pacht A, Obeid R, Lerner A. Range of neurologic disorders in patients with celiac disease. Pediatrics 2004;113:1672-6.

9. Catassi C, Rätsch IM, Fabiani E, et al. Coeliac disease in the year 2000: exploring the iceberg. Lancet 1994;343:200-3.

10. Hadjivassiliou M, Mäki M, Sanders DS, et al. Autoantibody targeting of brain and intestinal transglutaminase in gluten ataxia. Neurology 2006;66:373-7.

11. Hadjivassiliou M, Gibson A, Davies-Jones GA, et al. Does cryptic gluten sensitivity play a part in neurological illness? Lancet 1996;347:369-71.

12. Cooper BT, Holmes GK, Ferguson R, et al. Gluten-sensitive diarrhea without evidence of celiac disease. Gastroenterology 1981;81:192-4.

13. Sapone A, Lammers KM, Mazzarella G, et al. Differential mucosal IL-17 expression in two gliadin-induced disorders: gluten sensitivity and the autoimmune enteropathy celiac disease. Int Arch Aller A Imm 2010;152:75-80.

14. Sapone A, Bai JC, Ciacci C, et al. Spectrum of gluten related disorders: consensus on new nomenclature and classification. BMC Med 2012;10:13.

15. Catassi C, Bai JC, Bonaz B, et al. Non-celiac gluten sensitivity: the new frontier of gluten related disorders. Nutrients 2013;5:3839-53.

16. Brottveit M, Beitnes AC, Tollefsen S, et al. Mucosal cytokine response after short-term gluten challenge in celiac disease and non-celiac gluten sensitivity. Am J Gastroenterol 2013;108:842-50.

17. Berio A, Badolati G, Mangiante G, et al. Anti-tissue transglutaminase antibodies and EEG pattern in celiac patients on prolonged gluten-free diet. J Biol Res - Boll Soc It Biol Sper 2013;86:12-5.

18. Vezzani A, French J, Bartfai T, Baram TZ. The role of inflammation in epilepsy. Nat Rev Neurol 2011;7:31-40.

19. Emanuel B, Lieberman AD. Electroencephalogram changes in celiac disease. J Pediatr 1963;62:435-7.

20. Vezzani A, Balosso S, Ravizza T. The role of cytokines in the pathophysiology of epilepsy. Brain Behav Immun 2008;22:797-803.

21. Ravizza T, Gagliardi B, Noé F, et al. Innate and adaptive immunity during epileptogenesis and spontaneous seizures: evidence from experimental models and human temporal lobe epilepsy. Neurobiol Dis 2008;29:142-60.

22. Piani D, Frei K, Do KQ, et al. Murine brain macrophages induced NMDA receptor mediated neurotoxicity in vitro by secreting glutamate. Neurosci Lett 1991;133:159-62.

23. Berio A, Piazzi A. A case of Kearns-Sayre syndrome with autoimmune thyroiditis and possible Hashimoto encephalopathy. Panminerva Med 2002;44:265-9.

24. Berio A, Mangiante G, Piazzi A. Association of severe myoclonic epilepsy of infancy (SMEI) with probable autoimmune lymphoproliferative syndrome-variant. Pediatr Med Chir 2014;36:212-20. 